\title{
Neuromuscular block-
} ing effects of rocuronium during desflurane, isoflurane, and sevoflurane anaesthesia

\author{
Hinnerk Wulf $M D$, \\ Thomas Ledowski MD, \\ Ulf Linstedt $M D$, \\ Dietfrid Proppe MD, * \\ Delia Sitzlack INTERN
}

Purpose: To determine the magnitude of the potentiation of rocuronium by desflurane, isoflurane and sevoflurane 1.5 MAC anaesthesia.

Methods: In a prospective, randomised, study in 80 patients, the cumulative dose-effect curves for rocuronium were determined during anaesthesia with desflurane, sevoflurane and isoflurane (with $\mathrm{N}_{2} \mathrm{O} 70 \%, 15$ min steady state) or total intravenous anaesthesia (TIVA) using propofolfentanyl. Neuromuscular block was assessed by acceleromyography (TOF-Guard $(8)$ after train-of-four (TOF) stimulation of the ulnar nerve ( $2 \mathrm{~Hz}$ every I $2 \mathrm{sec}, 200$ $\mu \mathrm{sec}$ duration). Rocuronium was administered in increments of $100 \mu \mathrm{g}^{\mathrm{kg}} \mathrm{g}^{-1}$ until first twitch $\left(T_{1}\right)$ depression $>95 \%$. Results: Rocuronium led to more pronounced $T$, depression with desflurane or sevoflurane anaesthesia than with TIVA. The $\mathrm{ED}_{50}$ and $\mathrm{ED}_{95}$ were lower during desflurane $\left(95 \pm 25\right.$ and $\left.190 \pm 80 \mu \mathrm{g} \cdot \mathrm{kg}^{-1}\right)$ and sevoflurane ( $120 \pm$ 30 and $\left.210 \pm 40 \mu \mathrm{gkg}^{-1}\right)$ than with TIVA $\left(150 \pm 40\right.$ and $\left.310 \pm 90 \mu \mathrm{gkg}^{-1}\right)(P<.01)$, while the difference was not significant for isofurane (130 40 and $\left.250 \pm 90 \mu \mathrm{g}^{-1} \mathrm{~kg}^{-1}\right)$. Following equi-effective dosing $\left(T_{1}>95 \%\right)$ the duration to $25 \% \mathrm{~T}$, recovery, recovery index $(25 / 75)$, and $\mathrm{TOF}_{0.70}$ was: $13.2 \pm 1.8,12.7 \pm 3.4$, and $26.9 \pm 5.7 \mathrm{~min}$ during anaesthesia with desflurane; $15.5 \pm 5.0,11.4 \pm 3.8$ and $31.0 \pm 6.0 \mathrm{~min}$ with sevoflurane; $13.9 \pm 4.7,10.7$ \pm 3.3 , and $26.3 \pm 8.9 \mathrm{~min}$ with isoflurane; and $13.9 \pm 3.9,11.3 \pm 5.7$, and $27.5 \pm 8.2 \mathrm{~min}$ with TIVA anaesthesia (P: NS).

Conclusion: Interaction of rocuronium and volatile anaesthetics resulted in augmentation of the intensity of neuromuscular block but did not result in significant effects on duration of or recovery from the block.

Objectif : Déterminer l'importance de la potentialisation du rocuronium lors de l'anesthésie utilisant une CAM de 1,5 de desflurane, d'isoflurane et de sévoflurane.

Méthode : Dans une étude randomisée et prospective chez 80 patients, les courbes cumulatives de l'effet en fonction de la dose pour le rocuronium ont été déterminées pendant l'anesthésie avec du desflurane, du sévoflurane et de l'isoflurane (avec $\mathrm{N}_{2} \mathrm{O} 70 \%$, à l'état d'équilibre après $15 \mathrm{~min}$ ) ou pendant l'anesthésie exclusivement intraveineuse (AEI) utilisant du propofol et du fentanyl. La profondeur du bloc neuromusculaire a été mesurée à l'aide d'un accéléromyographe (TOF-Guard $\circledast$ ) après une stimulation du nerf cubital en train de quatre (TDQ). $(2 \mathrm{~Hz}$ toutes les $12 \mathrm{~s}$, durée de $200 \mu \mathrm{s})$. Le rocuronium a été administré en accroissements de $100 \mu \mathrm{g} \cdot \mathrm{kg}^{-1}$ jusqu'à ce que la première réponse $\left(R_{1}\right)$ atteigne une réduction $>95 \%$.

Résultats : Le rocuronium provoque des dépressions de $R$, plus marquée lors de l'anesthésie avec le desflurane ou le sévoflurane que lors de l'AEI. Les $\mathrm{ED}_{50}$ et $\mathrm{ED}_{95}$ ont été plus faibles avec desflurane (95 \pm 25 et 190 $\left.\pm 80 \mu \mathrm{gg}^{-1}\right)$ et sévoflurane $\left(120 \pm 30\right.$ et $\left.210 \pm 40 \mu \mathrm{g}^{-\mathrm{kg}^{-}}\right)$qu'avec l'AEl (150 \pm 40 et $\left.310 \pm 90 \mu \mathrm{g}^{\prime} \mathrm{kg}^{-1}\right)(P$ $<, 01$ ), tandis que la différence n'était pas significative avec isoflurane (130 \pm 40 et $\left.250 \pm 90 \mu \mathrm{g}^{-\mathrm{kg}^{-1}}\right)$. A la suite d'un dosage à effet équivalent $\left(R_{1}>95 \%\right)$ la durée de la récupération à $25 \% R_{1}$, l'index de récupération $(25 / 75)$ et le train de quatre 0,70 etaient: $13,2 \pm 1,8 ; 12,7 \pm 3,4$ et $26,9 \pm 5,7$ min pendant l'anesthésie avec desflurane; $15,5 \pm 5,0 ; 11,4 \pm 3,8$ et $31,0 \pm 6,0 \mathrm{~min}$ avec le sévoflurane; $13,9 \pm 4,7 ; 10,7 \pm 3,3$ et $26,3 \pm 8,9 \mathrm{~min}$ avec l'isoflurane; enfin, $13,9 \pm 3,9 ; 11,3 \pm 5,7$ et $27,5 \pm 8,2$ min avec l'AEI (P: NS).

Conclusion : Linteraction du rocuronium et des anesthésiques volatils a provoqué l'augmentation de l'intensité du bloc neuromusculaire mais n'a pas eu d'effet significatif sur la durée du bloc ou sur la récupération qui a suivi.

From the Department of Anaesthesiology and Intensive Care and the Department of Internal Medicine ${ }^{*}$ Nephrology, Hospital of the Christian-Albrechts-University, Kiel, Germany.

Address correspondence to: Priv. Doz. Dr. Med. Hinnerk Wulf, Department of Anaesthesiology, University Hospital, Schwanenweg 21, D24105 Kiel, Germany. Phone: 49-431-597-2991; Fax: 49-431-597-3002; E-mail: WULF@ANAESTHESIE.UNI-KIEL.DE

Presented, in part, at the German Congress of Anaesthesiologists 1997 Hamburg, Germany and at the ASA- meeting 1997, San Diego CA. Acceleromyographs and related software provided by Organon Technika (Eppelheim, Germany).

Accepted for publication March 14, 1998. 


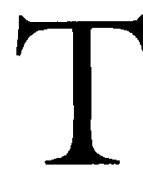

$\mathrm{HE}$ neuromuscular blocking effects of muscle relaxants are enhanced by volatile anacsthetics, a phenomenon called "potentiation". The magnitude of this effect on the dose-response curve has not been investigated systematically for the recently introduced agent, rocuronium. Rocuronium is a non-depolarising steroidal muscle relaxant with a shorter onset of action than other available non-depolarising relaxants. ${ }^{2}$ The new volatile agents, sevoflurane and desflurane, have a low blood-gas solubility resulting in rapid uptake and elimination. ${ }^{3,4}$ Their physicochemical properties allow a fast recovery, thus making both agents suitable for day case surgery. Underestimation or ignoring of the enhancement of neuromuscular block by volatile anaesthetics during short procedures could result in inadvertent prolonged duration of relaxation. Therefore, the interaction of rocuronium with the new volatile anaesthetics, desflurane and sevoflurane, and with isoflurane was investigated and compared with the neuromuscular blocking effects of rocuronium during total intravenous anaesthesia (TIVA).

\section{Methods}

The investigation was planned in accordance with the recommendations outlined in "Good Clinical Research Practice (GCRP) in pharmacodynamic studies of neuromuscular blocking agents".5

Sample size estimation (power analysis) was based on the following previous results: The $\mathrm{ED}_{50}$ of rocuronium during halothane and enflurane anaesthesia is approximately $100 \mu \mathrm{g} \pm 10 \mu \mathrm{g}$ (SD). ${ }^{6}$ The time required for the first twitch $\left(\mathrm{T}_{1}\right)$ to recover to $75 \%$ after complete relaxation following continuous infusion of rocuronium was $30.2 \pm 6.1$ min during TIVA. ${ }^{7}$ In another study recovery took $42 \pm 9 \mathrm{~min}$ after complete relaxation following a single dose of $0.6 \mathrm{mg} \cdot \mathrm{kg}^{-1}$ during anaesthesia with isoflurane. ${ }^{8}$ Considering a difference of $20 \%$ in potency or recovery time to be of clinical importance and assuming a standard deviation of approximately $10-20 \%$ of the mean, the calculated sample size would have to be at least 11 (6-20) patients per group for single comparison $(\alpha=0.05 ; \beta=$ 0.2 ). Since a comparison of several volatile anaesthetics with TIVA was planned and since some drop-outs were anticipated, a sample size of 20 patients per group was deemed appropriate.

Following ethics committee approval and written informed consent 80 consecutive Caucasian male or female adults (ASA 1 or 2) were included in this prospective randomised study. The patients were scheduled for minor elective ENT or ophthalmological surgery and were free from neuromuscular and endocrine diseases. Exclusion criteria were: body weight greater or less than $30 \%$ of the ideal, patients $<18 \mathrm{yr}$ or $>59 \mathrm{yr}$, pregnancy or breast-feeding, history or laboratory signs of renal (creatinine $>100 \mu \mathrm{mol} \cdot \mathrm{l}^{-1}$ $\left(>1.3 \mathrm{mg} \cdot \mathrm{dl}^{-1}\right)$ ) or hepatic disease $\left(\gamma-\mathrm{GT}>333 \mathrm{nkat} \cdot \mathrm{l}^{-1}\right.$ ( $\left.>20 \mathrm{U} \cdot \mathrm{l}^{-1}\right)$ ), paresis, bedridden patients, intake of medication known to interact with non-depolarising muscle relaxants and allergic diathesis.

Cumulative dose-effect curves for rocuronium were determined during anaesthesia with 1.5 MAC (minimal alveolar concentration, desflurane $(4.2 \%$ ), isoflurane $(0.75 \%)$, and sevoflurane $(1.05 \%)$ in nitrous oxide $70 \%$ /oxygen $30 \%$, not age-adjusted) and compared with the potency determined in patients during TIVA with propofol/fentanyl. Premedication consisted of $20 \mathrm{mg}$ dichlorazepat po on the evening prior to surgery. Anaesthesia was induced with $2-2.5 \mathrm{mg} \cdot \mathrm{kg}^{-1}$ propofol and $0.1 \mathrm{mg}$ fentanyl $i v$ in the arm opposite to that connected to the neuromuscular monitoring equipment. The volatile anaesthetics were administered starting with 2.5-3 MAC inspiratory concentration. This was reduced within the next minutes to 1.5 MAC. Inspiratory and end-tidal concentrations of the anaesthetics were measured (Capnomac (Datex)). All study groups received $\mathrm{O}_{2} / \mathrm{N}_{2} \mathrm{O} 30 / 70 \%$. End-tidal $\mathrm{PCO}_{2}$ was adjusted to between 4.3 and $4.7 \mathrm{kPa}(32$ and $35 \mathrm{mmHg}$ ). Body temperature and skin temperature above the monitored muscle were measured and kept $>35 \mathrm{C}$ and $32 \mathrm{C}$, respectively, by passive warming (wrapping of the patient and the arm in a cotton blanket). The blood pressure cuff was placed on the opposite arm. Light anaesthesia or moderate hypertension (> 120\% of baseline) were treated initially with $0.1 \mathrm{mg}$ fentanyl $i v$ and, if necessary, by increasing by $20 \%$ the end-tidal concentration of the volatile anaesthetic or the propofol infusion rate, respectively. Hypotension ( $<80 \%$ of baseline) was treated initially by infusion of fluids and then by decreasing by $20 \%$ the end-tidal concentration or the propofol infusion rate, respectively.

The left arm was attached to a special arm board (Armboard TOF-Guard $\otimes$, Biometer Int., Odense DK) for assessment of neuromuscular block using acceleromyography (AMG). ${ }^{9}$ The adductor pollicis muscle was monitored with the piezo-electric ceramic wafer placed at the distal interphalangeal joint of the thumb (TOF-Guard ${ }^{\circledR}$, Biometer Int., Odense DK). Train of four (TOF) stimulation of the ulnar nerve via surface stimulating electrodes placed at the wrist was used (supra-maximal square wave impulses with $2 \mathrm{~Hz}$, applied every $12 \mathrm{sec}, 200 \mu \mathrm{sec}$ duration). ${ }^{5}$ All data were stored electronically and downloaded into a computer programme for further analysis (TOF- 
Guard Card Reader 1.0 for Windows (Organon Teknika, Turnhout, Belgium)). Rocuronium was administered when neuromuscular response (stable control response in AMG for five minutes, a period that was demonstrated to be long enough for stabilization ${ }^{10}$ ) and equilibrium of inspiratory and endtidal concentration of volatile anaesthetics appeared stable ${ }^{\text {ll }}$ (Capnomac (Datex)). Cumulative increments ${ }^{12}$ of $100 \mu \mathrm{g} \cdot \mathrm{kg}^{-1}$ rocuronium were administered repeatedly (injection time $<5 \mathrm{sec}$ into a fast running iv line) until depression of the first twitch $z=95 \%$ was achieved. Repeated doses were administered at least two minutes apart and only if three consecutive twitches $\left(T_{1}\right)$ showed the same amplitude to document that a stable response was obtained between each dose. The time over which the doses were given was relatively short (four to eight minutes). In addition to the depression of the first twitch response, the following parameters of neuromuscular block were obtained during steady state anaesthesia: duration $25 \%$ (time after injection of the last cumulative dose until $25 \%$ recovery of $\mathrm{T}_{1}$ ), recovery index: $\mathrm{C}$ time of recovery of $\mathrm{T}_{1}$ from $25 \%$ to $75 \%$ ), interval $\mathrm{T}_{1} 25 \%$ to a $\mathrm{TOF}$ ratio of $0.7\left(\mathrm{TOF}_{0.7}\right)$. Instead of TOF 0.8 (as suggested by the GCRP guidelines ${ }^{5}$ ) TOF ratio 0.7 was used since, in some parients, the concentration of the volatile anaesthetic had been reduced already approaching the end of operation.

In cases of baseline shift (failure of $T_{1}$ to recover to between $85 \%$ and $110 \%$ with a TOF ratio $>0.8$ ), patients were excluded from further analysis. Individual dose-response curves were established by plotting the logarithm of the dose against the logit transform of the depression of $T_{1}$ relative to baseline ( $100 \%$ depression of $\mathrm{T}_{1}$ was adjusted to $99 \%, 0 \%$ to $1 \%$ respectively) using linear least squares regression ${ }^{5,12}$ Study-group dose response curves were established and $E D_{50}$ and $E D_{95}$ of rocuronium were calculated.

Statistical analysis: Data are presented as mean \pm SD. Statistical analysis was performed by one-way ANOVA (graph pad prism®, Kruskal-Wallis test and Dunn's post test for multiple comparison). $\alpha$ was set at $0.05, B$ was set at 0.2 .

\section{Results}

Patients in the study groups were similar in age, weight and sex distribution (Table I). Results from four patients were excluded from further analysis (drop-outs) because of deviation from the study protocol, baseline shift, and reduction of the concentration of the volatile anaesthetic $<1.2 \mathrm{MAC}$. In two patients in the isoflurane and in two patients in the sevoflurane group, the concentration of the volatile anaesthetic was reduced intermittently to $1.2 \mathrm{MAC}$ during the study because of arterial hypotension. In one patient in each of the isoflurane and desflurane groups the concentration had to be increased to 1.8 MAC intermittently. The propofol infusion rate was decreased by $20 \%$ in two patients and increased by $20 \%$ in one patient intermittently.

Rocuronium, in cumulative doses up to 300 $\mu \mathrm{g} \cdot \mathrm{kg}^{-1}$, led to a more pronounced depression of $T_{1}$ when anaesthesia was maintained with desflurane or sevoflurane than with TIVA (Table II) $(P<0.01)$. Multiples of $2.2 \pm 0.4,2.6 \pm 0.6$ and $3.4 \pm 0.7$ of the dose of $100 \mu \mathrm{g}$ were applied to obtain $\mathrm{Tl}<5 \%$. The $\mathrm{ED}_{50}$ and $\mathrm{ED}_{95}$ were lower during desflurane $(95 \pm 25$ and $190 \pm 80 \mu \mathrm{g} \cdot \mathrm{kg}^{-1}$ ) and sevoflurane anaesthesia $\left(120 \pm 30\right.$ and $\left.210 \pm 70 \mu \mathrm{g} \cdot \mathrm{kg}^{-1}\right)$ than with TIVA $\left(150 \pm 40\right.$ and $\left.310 \pm 90 \mu \mathrm{g} \cdot \mathrm{kg}^{-1}\right)(P<0.01)$ (Figure 1). Considering the correction for multiple comparison, the difference between the TIVA group and the isoflurane group $\left(\mathrm{ED}_{50} 130 \pm 40 ; \mathrm{ED}_{95} 250 \pm 90\right.$ $\left.\mu \mathrm{g} \cdot \mathrm{kg}^{-1}\right)$ was not significant $(P=0.08)$. The degree of potentiation (ratio of $\mathrm{ED}_{50}$ during TIVA/ $\mathrm{ED}_{50}$ curing volatile anaesthesia) was $1.6,1.3$, and 1.2 for desflurane, sevoflurane, and isoflurane respectively.

Following equi-effective dosing (depression of Tl to about $95 \%$, that is: halogenated groups received less drug) the recovery data duration $25 \%$, recovery index $25 / 75$, and $\mathrm{TOF}_{0.70}$ revealed no difference among the study groups (Table III).

\section{Discussion}

The mechanism by which volatile anaesthetic agents increase neuromuscular block is still under discussion. ${ }^{13}$ Our goal was to determine the influence of the newer volatile anaesthetics, desflurane and sevoflurane, as well as isoflurane on the dose response relationship of rocuronium compared to a TIVA-control. In the present study the neuromuscular blocking effect of rocuronium was enhanced by desflurane and sevoflurane, whereas the effect of isoflurane was less pronounced. In contrast to some of the previous studies on the interaction of volatile anaesthetics and neuromuscular blocking drugs (NMBD), no effect on the duration and recovery could be demonstrated.

TABLE I Demographic data of the patients enrolled (mean \pm SD)

\begin{tabular}{lllll}
\hline & male/female & Weight $[\mathrm{kg}]$ & height $[\mathrm{cm}]$ & age $[\mathrm{y}]$ \\
\hline Desflurane & $8 / 10$ & $73 \pm 14$ & $172 \pm 11$ & $44 \pm 14$ \\
Isoflurane & $13 / 6$ & $80 \pm 15$ & $174 \pm 9$ & $47 \pm 16$ \\
Sevoflurane & $11 / 9$ & $78 \pm 15$ & $175 \pm 11$ & $48 \pm 14$ \\
TIVA & $11 / 8$ & $73 \pm 12$ & $171 \pm 10$ & $42 \pm 15$ \\
\hline
\end{tabular}


TABLE II Neuromuscular blocking effects of rocuronium $\left(\mathrm{ED}_{50}\right.$ and $\left.\mathrm{ED}_{95}\right)$ Depression of the first twitch (\% of control) after 3 cumulative doses of $100 \mu \mathrm{g} \mathrm{kg}^{-1}$ rocuronium during desflurane, isoflurane, sevofluranc and total intravenous anaesthesia (TIVA). $\mathrm{ED}_{50}$ and $\mathrm{ED}_{95}$ were calculated after logit transformation. ${ }^{*} P<0.05$

\begin{tabular}{llllll}
\hline & \multicolumn{2}{l}{ Depression first twitch (\% of control) } & & & \\
& $100 \mu g \cdot k g^{-1}$ & $200 \mu g \cdot g^{-1}$ & $300 \mu g \cdot k g^{-1}$ & $E D_{50} \mu g \cdot k g^{-1}$ & $E D_{95} \mu g \cdot k g^{-1}$ \\
\hline Desflurane & $58 \pm 25^{*}$ & $95 \pm 7^{*}$ & $100 \pm 1^{*}$ & $95 \pm 25^{*}$ & $190 \pm 80^{*}$ \\
Isoflurane & $31 \pm 24$ & $78 \pm 21$ & $94 \pm 8$ & $130 \pm 40$ & $250 \pm 90$ \\
Sevofluranc & $45 \pm 26^{*}$ & $90 \pm 13^{*}$ & $98 \pm 5^{*}$ & $120 \pm 30^{*}$ & $210 \pm 40^{*}$ \\
TrVA & $14 \pm 24$ & $65 \pm 22$ & $90 \pm 10$ & $150 \pm 40$ & $310 \pm 90$ \\
\hline
\end{tabular}

TABLE III Duration and recovery of neuromuscular block during desflurane, isoflurane, sevoflurane and total intravenous anaesthesin following equi-effective doses of rocuronium.

\begin{tabular}{|c|c|c|c|c|c|}
\hline & $E D_{95} \mu g \cdot k g^{-1}$ & $\begin{array}{l}\text { Dose } \\
\text { Given }\end{array}$ & $\begin{array}{l}\text { Duration 25\% } \\
\text { [min] }\end{array}$ & $\begin{array}{l}\text { Recovery Index } 25 / 75 \\
{[\mathrm{~min}]}\end{array}$ & $\begin{array}{l}\text { TOF }_{0.70} \\
{[\mathrm{~min}]}\end{array}$ \\
\hline Destlurane & $190 \pm 80$ & $224 \pm 58$ & $13.2 \pm 1.8$ & $12.7 \pm 3.4$ & $26.9 \pm 5.7$ \\
\hline Isoflurane & $250 \pm 90$ & $287 \pm 68$ & $13.9 \pm 4.7$ & $10.7 \pm 3.3$ & $26.3 \pm 8.9$ \\
\hline Sevoflurane & $210 \pm 40$ & $265 \pm 49$ & $15.5 \pm 5.0$ & $11.4 \pm 3.8$ & $31.0 \pm 6.0$ \\
\hline TIVA & $310 \pm 90$ & $368 \pm 46$ & $13.9 \pm 3.9$ & $11.3 \pm 5.7$ & $27.5 \pm 8.2$ \\
\hline
\end{tabular}

Potency (augmentation of the depression of TI)

Sevoflurane and desflurane augmented the neuromuscular block of rocuronium. Using a single-dose technique for rocuronium, Oris and coworker ${ }^{6}$ reported a lower $\mathrm{ED}_{50}$ of $133\left(\mathrm{ED}_{90}\right.$ of 230$) \mu \mathrm{g} \cdot \mathrm{kg}^{-1}$ during halothane anaesthesia and $118(200) \mu g$ during enflurane anaesthesia compared with $167(300) \mu \mathrm{g}$ during total intravenous anaesthesia. Our data are in accordance with those of Muir et al. (enhancement by a factor of 1.25-1.4 compared with TIVA) ${ }^{14}$ In theory, assuming that the neuromuscular block starts at 70 $75 \%$ receptor occupancy and is half maximal at $87.5 \%$ receptor occupancy, the ratio $\mathrm{ED}_{95} / \mathrm{ED}_{50}$ should be 1.95. Our results demonstrate that this is true for rocuronium under four different anaesthetic conditions $(2.06,2.0,1.75,1.92)$.

Data for interaction of sevoflurane and rocuronium are lacking. Isoflurane and sevoflurane 1.5 $\mathrm{MAC}$ augmented the neuromuscular block produced by vecuronium, pancuronium and atracurium to a similar degree $^{15}$ as did sevoflurane and halothane for the block produced by vecuronium in children. ${ }^{16}$

\section{Interaction of rocuronium and volatile anaesthetics: duration and recovery}

Usually, potentiation of NMBD by volatile anaesthetics results predominantly in prolongation of the duration and recovery of neuromuscular block. ${ }^{17}$ These parameters were not prolonged significantly by volatile anaesthetics under the conditions of the present study. Saitoh et al. reported a minor prolongation of recovery from vecuronium-induced NMB during sevoflurane and enflurane by approximately $15 \% .{ }^{18}$ Duration and recovery time depend on the dose of the NMBD. ${ }^{1,19}$ The most probable reason for the longer duration of action observed in some studies compared with our results is that rocuronium was given in high doses (e.g. $600-900 \mu \mathrm{g} \cdot \mathrm{kg}^{-1}$ ), ${ }^{11,20}$ while the administration of moderate doses (e.g. up to $\left.300 \mu \mathrm{g} \cdot \mathrm{kg}^{-1}\right)^{21}$ leads to results very similar to those in the present study. Could a difference have been missed because of a type I error (small sample size)? Indeed, the standard deviations of duration and recovery data were higher than the SD used for the sample size estimation (data from mechanomyography, see below). Nevertheless, post-hoc analysis shows that the chance of missing a prolongation of $25 \%$ or more was $<20 \%$.

\section{Advantages and disadvantages of the techniques used in the present study:}

The efFect of Cumulative Dosing

The cumulative dose technique may underestimate the potency of neuromuscular blocking. However, administration was standardised and the use of volatile anaesthetics or TIVA was randomised; thus the cumulative pattern of rocuronium administration would have similar effects in all groups. In addition, the aim of the current study was to determine anaesthesia- 


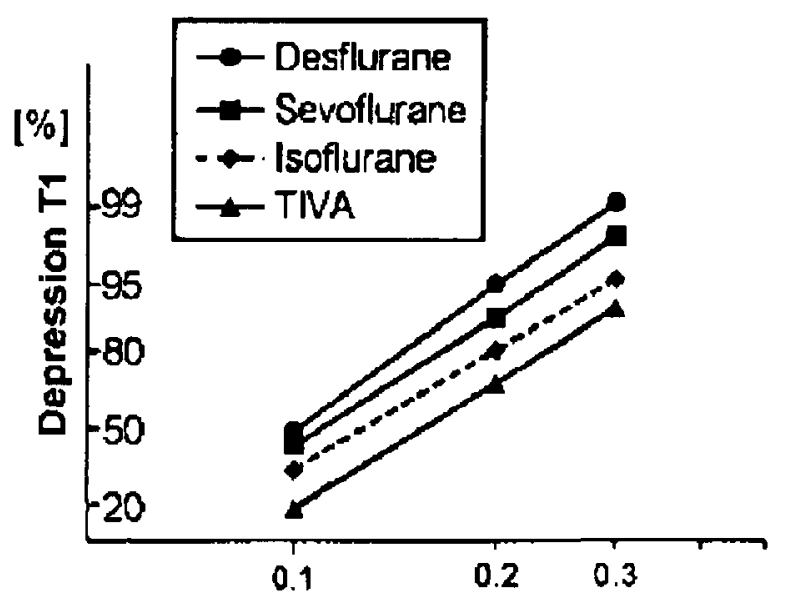

Rocuronium [mg* $\mathbf{k g}^{-1}$ ]

FIGURE 1 Log-probit plot comparing cumulative bolus doseresponse curves for the neuromuscular block induced by rocuronium during desflurane, sevoflurane, isoflurane (1,5 MAC) and total intravenous anaesthesia (TIVA). (depression was set at $100 \%$, if $>95 \%$ was reached with $200 \mu \mathrm{g} \cdot \mathrm{kg}^{-1}$ rocuronium already)

related effects of NMBD and not to provide absolute potency data. Nevertheless, the data presented by Oris et $a l^{6}{ }^{6}$ are similar to the results of the present study using a cumulative dosing technique during desflurane and sevoflurane anaesthesia. Furthermore, in the present study the total dose was given in increments and, therefore, recovery from the first dose could have started while the last dose was being administered. This could result in an underestimation of duration of action, particularly during the TIVA technique.

We used repetitive incremental dosing until 95\% depression of $T_{1}$ was obtained in an individual patient (equi- effective dose: identical end-point instead of identical doses). As a consequence, all halogenated groups received less drug. Using this approach of equi-effective dosing, enhancement of neuromuscular block could be demonstrated with regard to $\mathrm{ED}_{50}$ and $E_{95}$, whereas recovery times were not different among the volatile anaesthetics and TIVA groups. In contrast, if NMBDs are given in identical fixed doses regardless of the individual effecrive dose, differences in duration of action and recovery will result.

\section{THE INFLUENCE OF EQUILIBRATION TIME}

We started our measurements at least 15 to $20 \mathrm{~min}$ following induction of anaesthesia, since accelerometric monitoring results in stable effects after equilibration of $10 \mathrm{~min}$ or less. ${ }^{10}$ Inspiratory and end-tidal concentrations of volatile anaesthetics also indicated that steady state was approached, at least at the alveo- lar level. Diffusion of the inhaled anaesthetics into the muscle compartment is slow and requires about 30 $45 \mathrm{~min}$ to approach equilibration. Therefore, in the present study, this process was probably incomplete. Enhancement of neuromuscular block might still increase after more than one hour of anaesthesia with volatile agents. ${ }^{22-25}$ Studies beyond this time of final equilibrium are difficult to accomplish and bear little relevance to the routine clinical use of these agents. ${ }^{17}$ Due to the difference in the physicochemical properties, the equilibration between the muscle compartment and the end-tidal concentration is reached faster for desflurane and sevoflurane than for isoflurane. . $^{3,4,26}$ This phenomenon could explain the less pronounced effects of isoflurane in the present study. Nevertheless, our results are in agreement with those observed by Wright and colleagues in volunteers using a protocol with volatile anaesthetic administration for $>60 \mathrm{~min}$ before NMBD administration. ${ }^{26}$ They observed a $20 \%$ reduction in vecuronium requirement in the presence of 1.25 MAC desflurane compared with 1.25 MAC isoflurane. In contrast, Kumar et al. showed similar potentiation during desflurane and isoflurane anaesthesia after a stabilisation period of 10 min. ${ }^{11}$ Both studies were performed without a TIVA control group.

\section{Acceleromyography or mechanomyograpby?}

Mechanomyography still is considered to be the "gold standard" of neuromuscular monitoring and should be used for phase I or II studies. ${ }^{5}$ Acceleromyography and mechanomyography should not be used interchangeably, ${ }^{9,27}$ but acceleromyography can be used to evaluate further neuromuscular blocking agents unless the established guidelines are adhered to. ${ }^{5}$ Using acceleromyography there was good evidence of an interaction between volatile anaesthetics and rocuronium. The degree of augmentation of neuromuscular block was similar to the results of previous studies investigating rocuronium during anaesthesia with isoflurane using mechanomyography. Acceleromyography might have some limitations in regard to comparative measurements of duration and recovery, due to its greater drift and rather wide limits of agreement with mechanomyography. ${ }^{27}$

\section{Conclusion}

Under the conditions of the present study, the interaction of rocuronium and volatile anaesthetics results in an enhanced depression of the muscle twitch and a leftward shift in the dose response relationship in the first place. This should be taken into account when using rocuronium during desflurane or sevoflurane 
anaesthesia. Prolongation in the duration of action of, or in the recovery from neuromuscular block did not show with the present study using potency-adjusted dosing and acceleromyographic monitoring.

\section{Acknowledgements}

The help and constructive criticism of V. Nigrovic (Toledo, Ohio), JMKH Wierda (Groningen, The Netherlands) and G. Benad (Rostock, Germany) in preparing this manuscript is gratefully acknowledged.

\section{References}

1 Rupp SM, Miller RD, Gencarelli PJ. Vecuroniuminduced neuromuscular blockade during enflurane, isoflurane, and halothane anesthesia in humans. Anesthesiology 1984; 60: 102-5.

2 Huizinga ACT, Vandenbrom RHG, Wierda JMKH, Hommes FDM, Hennis PJ. Intubating conditions and onset of neuromuscular block of rocuronium (Org 9426); a comparison with suxamethonium. Acta Anacsthesiol Scand 1992; 36: 463-8.

3 Yasuda N, Lockbart SH, Eger EI II, et al. Comparison of kinctics of sevoflurane and isoflurane in humans. Anesth Analg 1991; 72: 316-24.

4 Tasuda N, Lockbart SH, Eger EI II, et al. Kinetics of desflurane, isoflurane, and halothane in humans. Anesthesiology 1991; 74: 489-98.

5 Viby-Mogensen J, Engbaek J, Eriksson LI, et al. Good clinical research practice (GCRP) in pharmacodynamic studies of neuromuscular blocking agents. Acta Anaesthesiol Scand 1996; 40: 59-74.

6 Oris B, Crul JF, Vandermeersch E, Van Aken H, Van Egmond J, Sabbe MB. Muscle paralysis by rocuronium during halothane, enflurane, isoflurane, and total intravenous anesthesia. Anesth Analg 1993; 77: 570-3.

7 Plaud B, Proost JH, Wierda JMKH, Barre J, Debaene B, Meistelman $C$. Pharmacokinetics and pharmacodynamics of rocuronium at the vocal cords and the adductor pollicis in humans. Clin Pharmacol Ther 1995; 58 : 185-91.

8 Cooper RA, Maddineni VR, Mirakbur RK, Wierda $J M K H$, Brady $M$, Fitzpatrick KTJ. Time course of neuromuscular effects and pharmacokinetics of rocuronium bromide (Org 9426) during isoflurane anaesthesia in patients with and without renal failure. $\mathrm{Br} J$ Anaesth $1993 ; 71: 222-6$.

9 Viby-Mogensen J, Jensen E, Werner M, Kirkegaard Nielsen $H$. Measurement of acceleration: a new method of monitoring neuromuscular function. Acta Anaesthesiol Scand 1988; 32: 45-8.

10 Girling $K J$, Mahajan $R P$. The effect of stabilization on the onset of neuromuscular block when assessed using accelerometry. Anesth Analg 1996; 82; 1257-60.
11 Kumar N, Mirakhur RK, Symington MJ, McCarthy GJ. Potency and time course of action of rocuronium during desflurane and isoflurane anaesthesia. $\mathrm{Br} \mathrm{J}$ Anaesth 1996; 77: 488-91.

12 Donlon JV Jr, Savarese J, Ali HH, Teplik RS. Human dose-response curves for neuromuscular blocking drugs. A comparison of two methods of construction and analysis. Anesthesiology 1980; 53: 161-6.

13 Pollard BJ. Interactions involving relaxants. In: Pollard BJ (Ed.) Applied Neuromuscular Pharmacology. Oxford University Press 1994; 202-28.

14 Muir AW, Anderson KA, Pow E. Interaction between rocuronium bromide and some drugs used during anaesthesia. Eur J Anaesthesiol 1994; 11(Suppl9): 93-8.

15 Vanlinthout LEH, Booij LHDJ, van Egmond J, Robertson EN. Effect of isoflurane and sevoflurane on the magnitude and time course of neuromuscular block produced by vecuronium, pancuronium and atracurium. Br J Anaesth 1996; 76: 389-95.

16 Taivainen T, Meretoja $O A$. The neuromuscular blocking effects of vecuronium during sevoflurane, halothane and balanced anaesthesia in children. Anaesthesia 1995; 50: 1046-9.

17 Agoston $S$. Interactions of volatile anacsthetics with rocuronium bromide in perspective. Eur $\mathrm{J}$ Anaesthesiol 1994; 11(Suppl9): 107-11.

18 Saitoh $Y$, Toyooka $H$, Amaba K. Recoveries of posttetanic twitch and train-of-four responses after administration of vecuronium with different inhalation anaesthetics and neuroleptanaesthesia. $\mathrm{Br}$ J Anaesth 1993; 70: 402-4.

19 Wierda JMKH, Proost JH, Schiere S, Hommes FDM. Pharmacokinetics and pharmacokinetic/dynamic relationship of rocuronium bromide in humans. Eur J Anaesthesiol 1994; 11(Supp19):66-74.

20 Von Klinzing $S$, Klein $U$, Eiselt $U$. Effect of rocuronium under sufentanil/isoflurane and sufentanil/propofol anaesthesia (German). Anaesthesiol Reanim 1996; 21: 149-52.

21 Servin FS, Lavaut E, Kleef U, Desmonts JM. Repeated doses of rocuronium bromide administered to cirrhotic and control patients receiving isoflurane.

Anesthesiology 1996; 84: 1092-100.

22 Sbanks $C A$, Fragen $R J$, Ling $D$. Continuous intravenous infusion of rocuronium (Org 9426) in patients receiving balanced, enflurane, or isoflurane anesthesia. Anesthesiology 1993; 78: 649-51.

23 Driessen J, Crul JF, Jansen R, van Egmond J. Isoflurane and neuromuscular blocking drugs. Anaesthesiology \& Intensive Care Medicine 1986; 182: 76-82. 
24 Meretoja OA, Wirtavuori $K$, Taivainen $T$, Olkkola KT. Time course of potentiation of mivacurium by halothane and isoflurane in children. $\mathrm{Br} J$ Anaesth 1996; 76: 235-8.

25 Kansanaho $M$, Olkkola $K T$. Quantifying the effect of isoflurane on mivacurium infusion requirements. Anaesthesia 1996; 51: 133-6.

26 Wright PMC, Hart $P$, Lau $M$, et al. The magnitude and time course of vecuronium potentiation by desflurane versus isoflurane. Anesthesiology 1995; 82: 404-11.

27 Harper NJN, Martlew R, Strang $T$, Wallace $M$. Monitoring neuromuscular block by acceleromyography: comparison of the mini-accelerograph with the myograph 2000. Br J Anaesth 1994; 72: 411-4. 